\title{
КЛЕТОЧНЫЙ СОСТАВ ПЕРИФЕРИЧЕСКОЙ КРОВИ У ОБЛУЧЁННЫХ ЛИЦ В ПЕРИОД, ПРЕДШЕСТВУЮЩИЙ ФОРМИРОВАНИЮ ЛЕЙКОЗОВ
}

\author{
(С Аклеев А.А. ${ }^{1,2}$, Долгушин И.И.
}

' Лаборатория молекулярно-клеточной радиобиологии

Уральского научно-практического центра радиационной медицины, Челябинск;

${ }^{2}$ кафедра микробиологии, вирусологии, иммунологии и клинической лабораторной диагностики Южно-Уральского государственного медицинского университета, Челябинск

E-mail: andrey.akleev@yandex.ru

По результатам 60-летнего наблюдения за жителями прибрежных сел реки Течи, подвергшихся хроническому радиационному воздействию, ретроспективно был проанализирован клеточный состав периферической крови у 57 человек, заболевших лейкозами (МКБ-9, рубрики 204-208). Анализ проведен для трех периодов: максимального радиационного воздействия (1950-1956 гг.), восстановления гемопоэза (1957-1970 гг.) и отдаленных последствий (после 1970 г.). Клеточный состав периферической крови у облученных лиц с лейкозами был также оценен в латентном периоде. У лиц, подвергшихся хроническому облучению (среднее значение поглощенной дозы на красный костный мозг составило $0,77 \pm 0,21 \Gamma$ р) и заболевших впоследствии лейкозами, не обнаружено каких-либо особенностей со стороны клеточного состава периферической крови во время максимального радиационного воздействия, восстановления кроветворения и отдаленных последствий, а также в латентном периоде лейкозов.

Ключевые слова: красный костный мозг, лейкоз, доза облучения, клеточный состав периферической крови.

\section{PERIPHERAL BLOOD CELLULAR COMPOSITION IN PERSONS EXPOSED DURING THE PERIOD PRECEDING LEUKEMIA DEVELOPMENT Akleyev A.A. ${ }^{1,2}$, Dolgushin I.I. ${ }^{2}$}

${ }^{1}$ Laboratory of Molecular-Cellular Radiobiology of Urals Research Center for Radiation Medicine, Chelyabinsk;

${ }^{2}$ Department of Microbiology, Virology, Immunology and Clinical Laboratory Diagnostics of Southern-Urals State Medical University, Chelyabinsk

Retrospective analysis of the peripheral blood cellular composition in 57 persons diagnosed with leukemia (ICD-9, codes 204-208) was performed based on a 60-year follow-up of the Techa riverside residents affected by chronic radiation exposure. The analysis covered three periods: that of maximal radiation exposure (1950-1956), of hematopoiesis recovery (1957-1970), and of late effects (after 1970). Peripheral blood cellular composition in exposed persons was also studied during the latency period. People affected by chronic radiation exposure (mean absorbed dose to red bone marrow amounted to $0.77 \pm 0.21$ Gy) and diagnosed with leukemia did not exhibit any peculiar features of cellular composition of blood during the period of maximal radiation exposure, hematopoiesis recovery, late effects, and also during the latency period of leukemia.

Keywords: red bone marrow, leukemia, exposure dose, peripheral blood cellular composition.

Одним из наиболее неблагоприятных отдаленных медицинских последствий действия ионизирующей радиации на организм человека является развитие злокачественных новообразований. Эпидемиологические наблюдения, проведенные в различных группах облученных лиц, свидетельствовали о наиболее высоком радиационном риске развития у них лейкозов $[9,12,13]$.

Большой практический интерес представляет наблюдение за жителями прибрежных сел реки Течи, подвергшимися многолетнему радиационному воздействию преимущественно с низкой мощностью дозы вследствие сбросов жидких радиоактивных отходов Производственным объединением «Маяк» в реку Течу. Известно, что критическими системами у жителей прибрежных сел являлись кроветворная и иммунная $[1,2,11]$. Это обусловлено в первую очередь значительным вкладом внутреннего облучения красного костно- го мозга (ККМ), в котором находятся гемопоэтические стволовые клетки (ГСК) и клеткипредшественники гемо- и иммунопоэза. Вовторых, высокой радиочувствительностью клеток кроветворной и иммунной системы. Внутреннее облучение ККМ было преимущественно обусловлено остеотропными радионуклидами стронция $\left({ }^{89} \mathrm{Sr}\right.$ и $\left.{ }^{90} \mathrm{Sr}\right)$, доля которых в сбросах была существенной [1]. Внешнее $\gamma$-облучение, вызванное главным образом ${ }^{137} \mathrm{Cs},{ }^{95} \mathrm{Zr},{ }^{95} \mathrm{Nb},{ }^{106} \mathrm{Ru}$, способствовало относительно равномерному облучению всего организма.

Результаты эпидемиологических исследований, проведенных в отдаленные сроки (спустя 6065 лет после начала облучения), свидетельствовали о существенном повышении радиационного риска развития лейкозов у жителей прибрежных сел реки Течи. Атрибутивный риск их достигал 50\% [12]. Исследования, проведенные в более 
ранние годы $[1,2,4,10,11]$, позволили отметить длительное угнетение гемопоэза и функционального состояния иммунной системы у лиц, доза облучения ККМ у которых превышала 400 мГр. Восстановление кроветворения и иммунологического статуса происходило медленно, что было обусловлено длительным облучением ККМ со снижающейся мощностью дозы за счет инкорпорированного в костной ткани основного дозообразующего радионуклида - $\beta$-излучателя ${ }^{90} \mathrm{Sr}$ (период полураспада $-28,1$ года) [6].

В данной работе проведен ретроспективный анализ клеточного состава периферической крови (КСПК) у жителей прибрежных сел реки Течи, которые в последующем заболели лейкозами. Исследование имело своей целью изучить возможную связь ранних изменений гемопоэза, которые имели место в период максимального радиационного воздействия (1950-1956 гг.), с развитием такого отдаленного фатального радиационного эффекта, как лейкоз. Значительный интерес представляло исследование КСПК и в периоде восстановления гемопоэза (1957-1970 гг.). В этом периоде после снижения мощности дозы облучения ККМ до 100 мГр/год и ниже у облученных лиц нередко отмечались лейкоцитоз, преимущественно за счет повышения числа нейтрофильных гранулоцитов в крови, а также палочкоядерный сдвиг влево [2]. Состояние КСПК оценивалось также и в отдаленные сроки после начала радиационного воздействия (после 1970 года), когда в подавляющем большинстве случаев имело место восстановление гемопоэза, однако частота умеренной лейкопении $\left(<4,0 \times 10^{9} /\right.$ л) сохранялась повышенной до 2002 года [1].

\section{МАТЕРИАЛЫ И МЕТОДЫ ИССЛЕДОВАНИЯ}

Всего за период с 1950-го по 2015 г. в когорте реки Течи (КРТ), которая включает 29730 постоянных жителей прибрежных сел, было зарегистрировано 99 случаев лейкозов. В настоящий анализ было включено 57 случаев лейкозов (МКБ-9, рубрики 204-208), которые были зарегистрированы у лиц, регулярно наблюдавшихся в клинике Уральского научно-практического центра радиационной медицины (УНПЦ РМ) ФМБА России и проходивших гематологические исследования. Исследуемая группа включала 22 случая (38,6\%) острых лейкозов (коды по МКБ-9 204.0$208.0)$ и 35 случаев $(61,4 \%)$ хронических лейкозов (коды по МКБ-9 205.1-208.1). Диагноз лейкоза во всех случаях был морфологически верифицирован. Из анализа исключались случаи лейкозов у мигрантов, которые выехали за пределы территории наблюдения (Челябинская и Курганская об- ласти). Из исследования также были исключены случаи хронического лимфолейкоза (рубрика по МКБ-9 204.1), который, согласно современным представлениям, не индуцируется ионизирующей радиацией. Таким образом, в исследование включались только те случаи лейкозов, которые могли быть потенциально индуцированы ионизирующей радиацией [14].

В состав группы сравнения были включены облученные жители прибрежных сел реки Течи, которые также проходили регулярное наблюдение в период с 1951-го по 2015 г. в клинике УНПЦ РМ (до 1955 г. исследования проводились в экспедиционных условиях), но у которых не было зарегистрировано лейкозов, злокачественных новообразований и аутоиммунных заболеваний. В исследование включались анализы крови, проведенные при отсутствии острых воспалительных и инфекционных заболеваний, а также вне обострения хронических воспалительных заболеваний, беременности и других состояний, которые могли оказать влияние на КСПК. Чтобы исключить влияние возраста, пола, дозы облучения ККМ, группа сравнения формировалась методом «копия-кара» по вышеуказанным параметрам. При формировании группы сравнения также учитывался этнический фактор. Характеристика обследованных лиц по полу, возрасту, этнической принадлежности и поглощенной дозе облучения ККМ представлена в таблице 1.

Как видно из таблицы 1, 31 случай лейкозов был зарегистрирован у женщин $(54,4 \%), 26$ случаев - у мужчин $(45,6 \%)$. Средний достигнутый возраст на момент установления диагноза лейкоза составил 57 лет (возрастной диапазон 13-82 лет). Среди больных лейкозами лица славянской этнической группы (в основном русские) - 34 человека $(59,7 \%)$ превалировали над представителями тюркской (главным образом татары и башкиры) 23 человека (40,3\%). Индивидуальные значения дозы облучения ККМ, рассчитанные с использованием дозиметрической системы реки Течи TRDS-2009 [1] на время установления диагноза лейкоза, достигали 6,60 Гр (среднее значение $0,77 \pm 0,21 \Gamma$ p), а дозы облучения тимуса и периферических органов иммуногенеза $-0,54$ Гр (среднее значение $0,06 \pm 0,02$ ).

Клеточный состав периферической крови исследовали с использованием стандартных методов лабораторной диагностики. До 1968 г. уровень гемоглобина определялся с помощью гемометра Сали, количество эритроцитов и лейкоцитов - меланжерными методами в камере Горяева, тромбоцитов - в мазках, окрашенных по Фонио [7]. С 1969 г. клеточный состав периферической крови изучался на автоматических анализаторах «Celloscope», «Пикоскель» и «Digicell-1400», 
Характеристика обследованных лиц

\begin{tabular}{|c|c|c|}
\hline \multirow{3}{*}{ Пол } & Мужчины, \% & 45,6 (26 человек) \\
\hline & Женщины, \% & 54,4 (31 человек) \\
\hline & Всего, \% & 100 (57 человек) \\
\hline \multirow{4}{*}{ Средний возраст на момент обследования, лет } & 1950-1956 гг. & $\begin{array}{c}27,7 \pm 2,1 \\
(2-60)\end{array}$ \\
\hline & 1957-1970 гг. & $\begin{array}{c}33,0 \pm 2,3 \\
(8-78)\end{array}$ \\
\hline & 1971 г. и далее & $\begin{array}{c}47,7 \pm 2,2 \\
(27-75)\end{array}$ \\
\hline & латентный период & $\begin{array}{l}48,0 \pm 4,0 \\
(10-103)\end{array}$ \\
\hline \multicolumn{2}{|l|}{ Средний возраст на момент установления диагноза, лет } & $\begin{array}{c}57,0 \pm 2,2 \\
(13-82)\end{array}$ \\
\hline \multirow{2}{*}{ Этническая группа } & славяне & 59,7 (34 человека) \\
\hline & тюрки & 40,3 (23 человека) \\
\hline \multirow{2}{*}{$\begin{array}{l}\text { Кумулятивная доза облучения ККМ, Гр } \\
\text { Кумулятивная доза облучения тимуса и периферических } \\
\text { органов иммуногенеза, Гр }\end{array}$} & & $\begin{array}{c}0,77 \pm 0,21 \\
(0,001-6,60) \\
\end{array}$ \\
\hline & & $\begin{array}{c}0,06 \pm 0,02 \\
(0,001-0,54)\end{array}$ \\
\hline
\end{tabular}

уровень гемоглобина определялся гемоглобинцианидным методом [5] и на анализаторе «Digicell1400». Подсчет лейкоцитарной формулы крови во все сроки проводили методом световой микроскопии в мазках, окрашенных по методу Романовского-Гимза [5].

В период с 1950-го по 1956 г. в исследование включались анализы крови, которые были проведены наиболее рано после максимальных сбросов в 1951 году. В период восстановления гемопоэза (1957-1970 гг.) и в отдаленном периоде (после 1970 года) в анализ включались исследования, проведенные в середине изучаемого периода. Интерес представляло исследование КСПК у лиц, больных лейкозами, в латентном периоде. Как известно, лейкоз, как правило, диагностируется при наличии у больного клинических проявлений заболевания, поэтому анализ гематологических показателей в предлейкозном периоде мог бы позволить оценить возможные биомаркеры для диагностики лейкозов на ранних стадиях, когда еще нет клинических проявлений заболевания. Латентный период для развития лейкозов у жителей прибрежных сел реки Течи принимался равным 3 годам.

Характер распределения исследуемых показателей в группах обследованных лиц проводился с использованием критерия Шапиро-Уилка. Поскольку распределение не всегда было нормальным, статистическую обработку данных проводили с использованием непараметрических методов анализа. Базовый статистический анализ включал в себя расчет средних значений показателей, ошибок средних с указанием диапазонов вариа- бельности индивидуальных значений показателей. Сравнение несвязанных групп (облученных, имевших впоследствии лейкозы, и облученных без лейкозов) проводилось путем вычисления U-критерия Манна-Уитни. Нулевая гипотеза об отсутствии различий между сравниваемыми группами отвергалась при $\mathrm{p}<0,05$, и принималась альтернативная гипотеза о наличии статистически значимых различий [8]. Сравнение частот встречаемости тех или иных явлений в исследуемых группах проводилось путем вычисления критерия $\chi^{2}$ [3]. Статистическую обработку данных проводили при помощи табличного редактора Microsoft Excel 2013, а также пакета прикладных программ Statistica 10.0.

Работа одобрена этическим комитетом ФГБУН «Уральский научно-практический центр радиационной медицины» ФМБА России и выполнена по контракту № 27.501.14.2 от 25.02.2014 г. в рамках ФЦП «Обеспечение ядерной и радиационной безопасности на 2008 год и на период до 2015 года».

\section{РЕЗУЛЬТАТЫ ИССЛЕДОВАНИЯ И ИХ ОБСУЖДЕНИЕ}

В период максимальных сбросов в реку Течу (1950-1956 гг.) у облученных лиц, имевших впоследствии лейкозы, статистически значимо реже регистрировались случаи снижения уровня гемоглобина крови, выходящие за $1,5 \sigma$, среди женщин и достоверно чаще случаи эритроцитопений среди мужчин по сравнению с облученными, не имевшими в дальнейшем лейкозов. По остальным 
показателям крови не было отмечено статистически значимых отличий от группы сравнения. Средние значения уровня гемоглобина крови у женщин исследуемой группы были статистически значимо выше по сравнению с таковыми в группе сравнения. Не было отмечено статистически значимых отличий по остальным показателям.

В периоде восстановления кроветворения (1957-1970 гг.) в группе облученных лиц с лейкозами статистически значимо чаще, чем в группе сравнения, встречались случаи снижения уровня гемоглобина у мужчин. Наблюдаемые изменения со стороны системы крови сочетались с большей частотой встречаемости эритроцитозов у женщин в исследуемой группе относительно группы сравнения. Средние значения показателей системы крови претерпевали сходные с частотными изменения в исследуемой группе, что свидетельствовало об однонаправленном характере изменений этих показателей у большей части представителей исследуемой группы. В частности, средние значения уровня гемоглобина крови у мужчин были статистически значимо ниже относительно группы облученных мужчин без лейкозов. Напротив, среднее значение количества эритроцитов в крови у женщин - представителей исследуемой группы было несколько выше, чем в группе сравнения. У мужчин, составляющих исследуемую группу, отмечалось повышение средних значений СОЭ.

В отдаленные сроки после хронического радиационного воздействия у лиц, заболевших впоследствии лейкозами, не было отмечено статистически значимых отличий относительно группы сравнения в частотах встречаемости значений показателей, выходящих за 1,5б. В целом обращал на себя внимание относительно небольшой процент случаев выхода значений показателей системы крови за пределы $\mathrm{M} \pm 1,5 \sigma$. Это свидетельствовало, по-видимому, о восстановлении основных ростков гемопоэза после многолетнего радиационного воздействия. Средние значения уровня гемоглобина в эритроцитах, а также количества эритроцитов были выше у женщин, составивших исследуемую группу.

В латентном периоде, непосредственно предшествовавшем манифестации лейкозов, у представителей исследуемой группы отмечалась большая частота встречаемости случаев повышения СОЭ среди женщин относительно группы сравнения. Средние значения КСПК у лиц исследуемой группы в этом периоде не отличались от таковых в группе сравнения.

Изменения, обнаруженные со стороны КСПК у облученных лиц, у которых впоследствии развились лейкозы, не удалось возможным представить в виде какой-либо концепции, поскольку они носили разнонаправленный характер. Эти изме- нения регистрировались в основном со стороны эритроидного ростка кроветворения, были наиболее выражены в период максимального радиационного воздействия и заключались в основном в повышении частоты случаев эритроцитопений у мужчин и уменьшении частоты случаев снижения уровня гемоглобина у облученных женщин. Частота случаев снижения уровня гемоглобина в крови в обеих сравниваемых группах была наибольшей в период с 1950-го по 1956 г. и объяснялась, скорее всего, дефицитом в послевоенном рационе белков, витаминов и микроэлементов [1]. В период восстановления кроветворения (1957-1970 гг.), когда мощности дозы внешнего радиационного воздействия существенно снизились, у облученных мужчин, заболевших впоследствии лейкозами, отмечалась более высокая частота случаев снижения уровня гемоглобина, а у женщин более часто регистрировались эритроцитозы относительно группы сравнения. Увеличение числа эритроцитов в единице объема крови на фоне снижения уровня гемоглобина носило компенсаторно-приспособительный характер и, скорее всего, не было связано с действием радиационного фактора.

Таким образом, не было обнаружено какихлибо закономерных изменений со стороны КСПК у облученных лиц, заболевших впоследствии лейкозами не только во время максимального радиационного воздействия и в период восстановления гемопоэза, но и в отдаленные сроки по сравнению с группой сравнения, представленной людьми аналогичного возраста и пола и облученных в таких же дозах. Возможно, лимитирующим фактором являлся разнородный состав группы лейкозов, в которую вошли различные формы как острых лейкозов, так и хронических. В дальнейшем представляется необходимым выделить в исследуемой группе отдельные нозологические формы лейкозов, в частности хронический миелолейкоз (ХМЛ) и группу острых лейкозов, поскольку они демонстрируют наибольшую зависимость от дозы облучения.

Авторы благодарят зав. отделом «База данных «Человек» Н.В. Стариева за помощь в формировании исследуемьх групп.

\section{ЛИТЕРАТУРА / REFERENCES}

1. Аклеев А.В., Аклеев А.А., Андреев С.С., Блинова Е.А., Бугров Н.Г., Буртовая Е.Ю., Варфоломеева Т.А., Возилова А.В., Воробьёва М.И., Дёгтева М.О., Крестинина Л.Ю., Толстых Е.И., Шагина Е.Б., Шишкина Е.А. Последствия радиоактивного загрязнения реки Течи / под ред. А.В. Аклеева. - Челябинск : Книга, 2016. - 390 с. [Akleyev A.V., Akleyev A.A., Andreyev S.S., Blinova E.A., Bugrov N.G., Burtovaya E.YU., Varfolo- 
meyeva T.A., Vozilova A.V., Vorob'yëva M.I., Dyogteva M.O., Krestinina L.Yu., Tolstykh E.I., Shagina E.B., Shishkina E.A. Consequences of radioactive contamination of the Techa River. A.V. Akleyev, editor. Chelyabinsk : Kniga; 2016: 390 (in Russ.)].

2. Аклеев А.В., Варфоломеева Т.А. Состояние гемопоэза в условиях многолетнего облучения костного мозга у жителей прибрежных сел р. Теча // Радиационная биология. Радиоэкология. - 2007. - Т. 47, № 3. - C. 307-321. [Akleyev A.V., Varfolomeyeva T.A. The state of hemopoiesis under conditions of longterm bone marrow exposure in residents of the Techa riverside villages. Radiatsionnaya biologiya. Radioekologiya. 2007; 47 (3): 307-321 (in Russ.)].

3. Лемешко Б.Ю., Чимитова Е.В. О выборе числа интервалов в критериях согласия типа $\chi^{2} / /$ Заводская лаборатория. Диагностика материалов. 2003. - T. 69, № 1. - С. 61-67. [Lemeshko B.Yu., Chimitova E.V. On the choice of the number of intervals in the $\chi^{2}$. Zavodskaya laboratoriya. Diagnostika materialov. 2003; 69 (1): 61-67 (in Russ.)].

4. Медико-биологические и экологические последствия радиоактивного загрязнения реки Теча / под ред. А.В. Аклеева, М.Ф. Киселёва. - М. : Медбиоэкстрем, 2001. - 532 с. [Medico-biological and есоlogical consequences of radioactive contamination of the Techa River. A.V. Akleyev, M.F. Kiselyov, editors. - M. : Medbioekstrem; 2001: 532 (in Russ.)].

5. Меньшиков В.В., Делекторская Л.Н., Золотницкая Р.П., Андреева 3.М., Анкирская А.С., Балаховский И.С., Белокриниикий Д.В., Воропаева С.Д., Гаранина Е.Н., Лукичева Т.И., Плетнева Н.Г., Смоляниикий А.Я. Лабораторные методы исследования в клинике / под ред. В.В. Меньшикова. М. : Медицина, 1987. - 368 с. [Men'shikov V.V., Delektorskaya L.N., Zolotnitskaya R.P., Andreyeva Z.M., Ankirskaya A.S., Balakhovskiy I.S., Belokrinitskiy D.V., Voropayeva S.D., Garanina E.N., Lukicheva T.I., Pletneva N.G., Smolyanitskiy A.Ya. Laboratory methods of research in the clinic. V.V. Men'shikov, editor. M. : Meditsina; 1987: 368 (in Russ.)].

6. Моисеев А.А., Иванов В.И. Справочник по дозиметрии и радиационной гигиене. - М. : Энергоатомиздат, 1990. - 256 c. [Moiseyev A.A., Ivanov V.I. Handbook of dosimetry and radiation hygiene. - M. : Energoatomizdat; 1990: 256 (in Russ.)].
7. Предтеченский B.E. Руководство по клиническим лабораторным исследованиям / под ред. Л.Г. Смирновой, Е.А. Кост. - М. : Медгиз, 1960. 964 c. [Predtechenskiy V.E. Guidelines for Clinical Laboratory Research. L.G. Smirnova, E.A. Kost, editors. M. : Medgiz; 1960: 964 (in Russ.)].

8. Реброва О.Ю. Статистический анализ медицинских данных. Применение пакета прикладных программ STATISTICA. - М. : Медиа Сфера, 2002. 312 c. [Rebrova O.Yu. Statistical analysis of medical data. Application of the STATISTICA software package. M. : Media Sfera; 2002. 312 (in Russ.)].

9. Фильченков А.А. Молекулярно-эпидемиологические маркеры радиогенных гемобластозов // Радиационная биология. Радиоэкология. - 2016. - Т. 56, № $6 . \quad-\quad$ C. 570-582. - $\quad$. DOI: 10.7868/S0869803116060047. [Philchenkov A.A. Molecular epidemiological markers of radiation-induced hematologic malignancies. Radiatsionnaya biologiya. Radioekologiya. 2016; 56 (6): 570-582 (in Russ.)].

10. Akleyev A.V., Varfolomeyeva T.A. Dynamics of blood cell composition in residents of the Techa riverside villages // Acta Med. Nagasaki. - 2007. - Vol. 52, N 1. - P. 19-28. - DOI: 10.11343/amn.52.19.

11. Akleyev A.V., Veremeyeva G.A., Silkina L.A., Vozilova $A$. $V$. Long-term hemopoiesis and immunity status after chronic radiation exposure of red bone marrow in humans // Central European Journal of Occupational and Environmental Medicine. - 1999. - Vol. 5, N 2. P. 113-129.

12. Krestinina L.Yu., Davis F.G., Schonfeld S., Preston D.L., Degteva M.O., Epifanova S., Akleyev A.V. Leukaemia incidence in the Techa River Cohort: 1953-2007 // British Journal of Cancer. - 2013. - Vol. 109, N 11. - P. 2886-2893. - DOI: 10.1038/bjc.2013.614.

13. Schonfeld S.J., Krestinina L.Y., Epifanova S., Degteva M.O., Akleyev A.V., Preston D.L. Solid cancer mortality in the Techa River Cohort (1950-2007) // Radiation Research. - 2013. - Vol. 179, N 2. - P. 183189. - DOI: 10.1667/RR2932.1.

14. UNSCEAR. Epidemiologic studies of radiation and cancer. Report to the General Assembly with Annexes. - New York : United Nations, 2008. 